\title{
Correlation from Undiluted Vitreous Cytokines of Untreated Central Retinal Vein Occlusion with Spectral Domain Optical Coherence Tomography
}

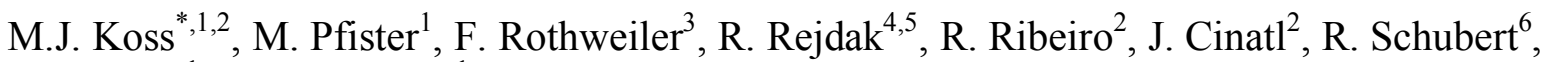 \\ T. Kohnen ${ }^{1}$ and F.H. Koch ${ }^{1}$ \\ ${ }^{I}$ Department of Ophthalmology, Goethe University, Frankfurt am Main, Germany \\ ${ }^{2}$ Doheny Eye institute, Los Angeles, USA \\ ${ }^{3}$ Department of Virology, Goethe University, Frankfurt am Main, Germany \\ ${ }^{4}$ Department of General Ophthalmology, Medical University in Lublin, Poland \\ ${ }^{5}$ Medical Research Centre, Polish Academy of Sciences, Warsaw, Poland \\ ${ }^{6}$ Department of Pediatric Pulmonology, Allergy and Cystic Fibrosis, Children's Hospital, Goethe University, Frankfurt \\ am Main, Germany
}

\begin{abstract}
Purpose: To correlate inflammatory and proangiogenic key cytokines from undiluted vitreous of treatmentnaïve central retinal vein occlusion (CRVO) patients with SD-OCT parameters.

Methods: Thirty-five patients (age 71.1 years, 24 phakic, 30 nonischemic) underwent intravitreal combination therapy, including a single-site 23-gauge core vitrectomy. Twenty-eight samples from patients with idiopathic, non-uveitis floaterectomy served as controls. Interleukin 6 (IL-6), monocyte chemoattractant protein-1 (MCP-1), and vascular endothelial growth factor (VEGF-A) levels were correlated with the visual acuity (logMar), category of CRVO (ischemic or nonischemic) and morphologic parameters, such as central macular thickness-CMT, thickness of neurosensory retinaTNeuro, extent of serous retinal detachment-SRT and disintegrity of the IS/OS and others.

Results: The mean IL-6 was $64.7 \mathrm{pg} / \mathrm{ml}(\mathrm{SD} \pm 115.8)$, MCP-1 1015.7 ( \pm 970.1$)$, and VEGF-A $278.4( \pm 512.8)$, which was significantly higher than the control IL-6 $6.2 \pm 3.4 \mathrm{pg} / \mathrm{ml}(\mathrm{P}=0.06)$, MCP-1 $253.2 \pm 73.5(\mathrm{P}<0.0000001)$ and VEGF-A 7.0 $\pm 4.9(\mathrm{P}<0.0006)$. All cytokines correlated highly with one another (correlation coefficient $\mathrm{r}=0.82$ for IL-6 and MCP-1; $\mathrm{r}=0.68$ for Il-6 and VEGF-A; $\mathrm{r}=0.64$ for MCP-1 and VEGF-A). IL-6 correlated significantly with CMT, TRT, SRT, dIS/OS, and dELM. MCP-1 correlated significantly with SRT, dIS/OS, and dELM. VEGF-A correlated not with changes in SD-OCT, while it had a trend to be higher in the ischemic versus the nonischemic CRVO group ( $\mathrm{P}=0.09)$.

Conclusions: The inflammatory cytokines were more often correlated with morphologic changes assessed by SD-OCT, whereas VEGF-A did not correlate with CRVO-associated changes in SD-OCT. VEGF inhibition alone may not be sufficient in decreasing the inflammatory response in CRVO therapy.
\end{abstract}

Keywords: Vitreous samples, CRVO, VEGF, MCP-1, IL-6, CBA, SD-OCT.

\section{INTRODUCTION}

Today, we can assess CRVO patients not only for changes in central macular thickness (CMT), but we can also conduct a detailed analysis of the neurosensory retina layers. Prognosis on visual acuity can be based upon the integrity of the IS/OS (photoreceptor inner and outer segments) and the external limiting membrane (ELM), which are important landmarks for good visual acuity rehabilitation. The development of subfoveal serous detachment seems thereby to be a potential negative clinical indicator [1-4]. In terms of

*Address correspondence to this author at the Department of Ophthalmology, Hospital of the Goethe University, Frankfurt am Main, Theodor Stern Kai 7, 60590 Frankfurt am Main, Germany; Tel: +49 - 69 6301 5649; Fax: +49 - 69 - 6301 5621; E-mail: Michael.Koss@me.com reducing the frequent intravitreal reinjections, careful SDOCT analysis allows for flexible anti-VEGF treatment, which has demonstrated significant functional and anatomic changes [5].

Macular edema secondary to central retinal vein occlusion (CRVO) occurs after multifactorial pathophysiologic changes, which affects intraocular cytokine levels [6-8]. Cytokines mediate between endothelial cells (EC) and inflammatory cells, which themselves interact with cytokine expression $[9,10]$. The prolonged contact of ECs to proinflammatory cytokines might promote more thrombosis on top of the initial venous occlusion. Upregulated vascular endothelial growth factor (VEGF) is thereby a known chemoattractant cytokine for macrophages and leukocytes 
and thus plays an important role in the pathophysiologic dysbalance of CRVO [11].

Funk et al. recently demonstrated that anti-VEGF monotherapy has impact on the expression of VEGF and inflammatory markers, including interleukin 6 (IL-6) and monocyte chemoattractant protein 1 (MCP-1) [6]. IL-6 thereby is a major promoter of acute-phase proteins. Secondly it mediates by VEGF the change from acute to chronic inflammation, as it thus combines the inflammatory process with angiogenesis [12]. It could be demonstrated that the severity of macular edema (ME) is correlated with cytokine dysbalance [13].

Our group has previously described the rationale and the clinical outcome of a combination therapy including a core vitrectomy with the application of anti-VEGF agents and steroids and we have described the differences of intravitreal cytokines in different RVO categories [14,15]. Thereby we were able to acquire undiluted vitreous from CRVO patients before the drug injection and correlate the load of cytokines with detailed intraretinal layer changes assessed with SDOCT.

\section{METHODS}

This study was conducted after local institutional review board (IRB) approval. Following the sixth revision of the Declaration of Helsinki each participating patient consented to the study.

Patients were included with a CRVO associated significant macular edema (CSME) involving the fovea, but a macular thickness of not more than $1000 \mu \mathrm{m}$, which led to a visual acuity of not worse than 2.0 LogMAR. Not included were patients with CRVO associated complications, like iris rubeosis or neovascularization. Excluded were additionally patients with a history of previous intravitreal drug injections or surgery.

Early Treatment Diabetic Retinopathy Study (ETDRS) best-corrected visual acuity (BCVA) was assessed at $5 \mathrm{~m}$ with stopping at three out of five optotypes and presented as the logarithm of the minimum angle of resolution (LogMAR).

A SD-OCT (SD-OCT; 3D OCT-2000; Topcon, Tokyo, Japan) scan depth of $2.3 \mathrm{~mm}$ with a horizontal resolution of $20 \mu \mathrm{m}$, and a longitudinal resolution of 5-6 $\mu \mathrm{m}$ was acquired at an A-scan speed of $27.000 \mathrm{~A}$ scans/second.

Consecutive sections and vertical and horizontal scans within the macular region were obtained by a well-trained OCT-certified technician (certification by the reading center, Vienna, Austria). Using OCT images, a standardized reading protocol was performed on OCT scans with a quality score over $16 \mathrm{~dB}$, including six measurements (Fig. 1):

1. Central macular thickness (CMT) was calculated as the distance of the inner limiting membrane (ILM) to the basal membrane (BM) of the retinal pigment epithelium (RPE) including all compartments in between.

2. Total retinal thickness (TRT) was defined as the biggest distance of the ILM to the BM of the RPE within the 3D scan field (127 A-scans), including
3. The Thickness of the neurosensory retina (TNeuro) and

4. The Subfoveal serous retinal thickness (SRT) and

5. The disintegrity of the inner and outer photoreceptor segments (dIS/OS)

6. The disintegrity of the external limiting membrane (dELM), both at the foveal region.

These measurements were reviewed with a caliper that was built into the software of the OCT machine by two retina specialists (M.P./F.K.) who were blinded to the visual acuity results and the results of the cytokine evaluation. Intergrader reliability $(\kappa)$ was assessed with a $\kappa$ value of 0.88 to 0.95 . Additionally, the A-scans were evaluated for the occurrence of intraretinal cysts or hyperreflective spots. To exclude false positive occurrence of disrupted/ disintegrated IS/OS or ELM sections due to overlying cystic edema or intraretinal bleeding a-scans were scrolled through the macular region. Ischemic retinopathy was declared with $>$ ten disc areas of nonperfusion with fluorescein angiography using the OIS WinStation $\left(11 \mathrm{~K}^{\mathrm{TM}}\right.$, CCS Pawlowski GmbH, Jena, Germany). In case of early, fresh CRVO with extensive hemorrhages blocking retinal parts, FA was delayed until bleeding cleared up.

The surgical technique that yielded the sample collection was described earlier [16]. Briefly, 0.6 to $0.8 \mathrm{ml}$ of undiluted vitreous fluid from the mid- to posterior vitreous cavity were extracted by an assistant under the guidance of the surgeon, who controlled the vitrector with a headset and a magnifying 28-diopter lens.

Samples from idiopathic, non-uveitic floaterectomy served as controls. All samples were saved prior to drug application and frozen at $-80^{\circ} \mathrm{C}$.

The cytometric bead array system with flex sets $\left(\mathrm{BD}^{\mathrm{TM}}\right.$, Heidelberg, Germany) was used to determine IL-6, MCP-1 and VEGF-A according to the manufacturer's instruction manual including the measurement on a FACSArray ${ }^{\mathrm{TM}}$ Bioanalyzer (BD ${ }^{\mathrm{TM}}$, Heidelberg, Germany) with FCAP array software (BD ${ }^{\mathrm{TM}}$, Heidelberg, Germany). The data were saved in EXCEL $^{\circledR}$ (Microsoft Office 2010, Redmond, USA) and statistically analyzed with Bias ${ }^{\circledR}$ software (Version 8.3.8, Epsilon, Darmstadt, Germany). The data had a nonparametrical distribution, which was checked with the David's test (error level of 5\%), thus the Wilcoxon-MannWhitney test could be applied with a P value of $<0.05$.

Spearman rank correlation coefficient was used to examine the relationship between the influences of the cytokines on other parameters, like or changes in SD-OCT.

\section{RESULTS}

\section{Patients}

The CRVO group (14 men and 21 women) was aged 71.1 \pm 11.7 years (mean \pm standard deviation - SD), and the control group (12 men and 16 women) was aged $66.2 \pm 7.9$ years $(\mathrm{P}=0.89$ and 0.17 , respectively, Table 1$)$. The visual acuity was $1.28 \pm 0.59 \operatorname{LogMAR}$ in the CRVO group and $0.51 \pm 0.22$ in the control group $(\mathrm{P}<0.001)$. Twenty-four out of 35 in the CRVO group and 8 out 28 in the control group 


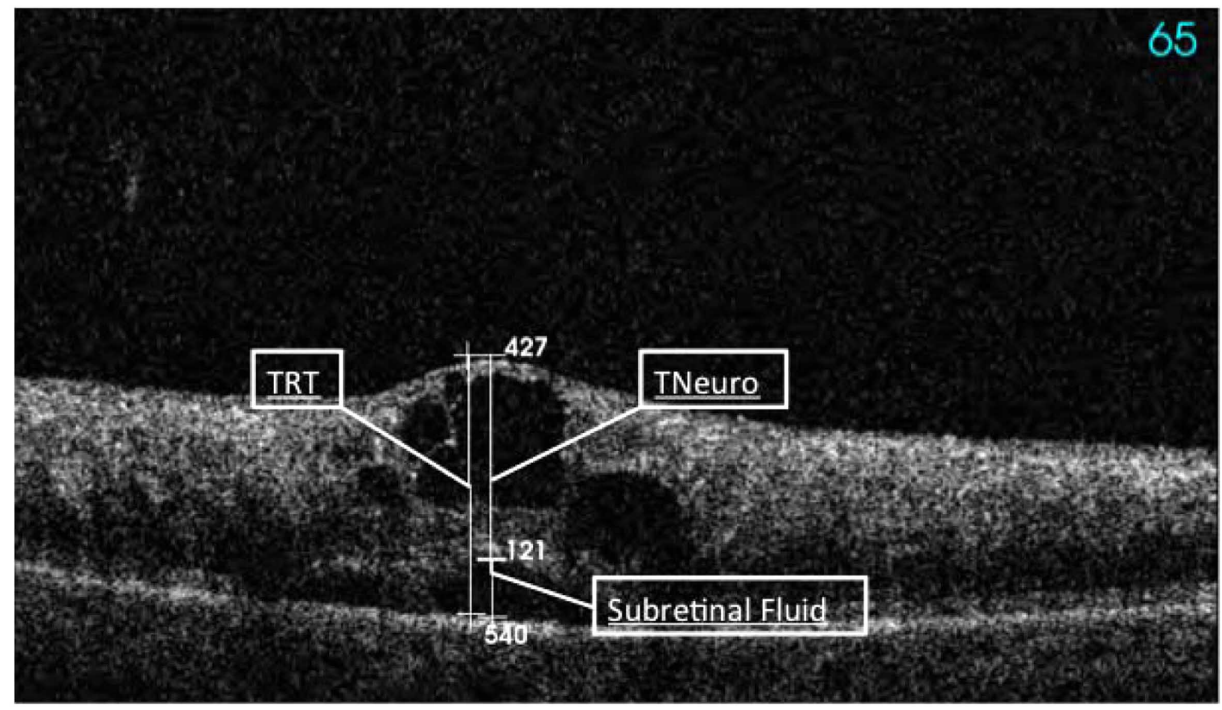

Fig. (1). Cystoid macular edema secondary to a fresh CRVO assessed by SD-OCT with marked total retinal thickness (TRT), thickness neurosensory (TNeuro), and subretinal thickness marked as subretinal fluid (SRT) measured in $\mu \mathrm{m}$

were phakic $(\mathrm{P}<0.005)$. Among the 35 CRVO patients, 30 were nonischemic. The duration of the CRVO was $7.4 \pm 3.5$ months for all CRVO patients and all were treatment naïve before study start. The patients were distributed in a subgroup of fresh CRVO with a duration of $5.1 \pm 2.0$ months $(\mathrm{n}=22)$ and a subgroup of old CRVO $(\mathrm{n}=13)$ with a duration of $11.2 \pm 1.6$ months after onset of the disease $(\mathrm{P}<0.001)$.

Table 1. Epidemiologics: Values in Mean $( \pm$ Standard Deviation), Blood Pressure in $\mathrm{mmHg}$, Duration of CRVO in Months, Ischemic Signs, Including Cotton Wools, Massive Intraretinal Haemorrhage, Enlarged Foveolar Avascular Zone, Capillary Drop-Outs, Area of Non-Perfusion $>5$ Disc Areas, Differences are Calculated with Wilcoxon-Mann-Whitney Test

\begin{tabular}{|llll|}
\hline & CRVO & Control & P Value \\
\hline \hline $\mathbf{N}$ & 35 & 28 & \\
Male/Female & $14 / 21$ & $12 / 16$ & 0.89 \\
Age in years & $71.1 \pm 11.7$ & $66.2 \pm 7.9$ & 0.17 \\
Blood Pressure & & & \\
Systolic & $141 \pm 18$ & $121 \pm 10$ & $<\boldsymbol{0 . 0 1}$ \\
Diastolic & $83 \pm 14$ & $75 \pm 8$ & 0.09 \\
Hypertension & 24 & 5 & $\mathbf{0 . 0 0 3}$ \\
Drug therapy & 22 & 3 & $\mathbf{0 . 0 0 4}$ \\
VA in logMar & $1.28 \pm 0.59$ & $0.51 \pm 0.22$ & $<\mathbf{0 . 0 0 1}$ \\
Pseudophakic/Phakic & $11 / 24$ & $20 / 8$ & $<\mathbf{0 . 0 0 5}$ \\
Duration of CRVO & $7.4 \pm 3.5$ & & \\
& & & \\
Type & Fresh & & \\
N & 22 & 13 & 0.96 \\
Ischemic/Nonischemic & $3 / 19$ & $2 / 11$ & $<\boldsymbol{0 . 0 0 1}$ \\
Duration of CRVO & $5.1 \pm 2.0$ & $11.2 \pm 1.6$ & \\
\hline
\end{tabular}

\section{Vitreal Cytokine Levels}

The mean IL-6 vitreal, MCP-1 and VEGF-A levels can be found in Table 2 and Fig. (2).

The IL-6 level was $66.8 \pm 124.6$ (CI 20.3-113.4) in the nonischemic CRVO group, the MCP-1 level was $1043.3 \pm$ 
Table 2. Characteristics of the SD-OCT Measurements (Please See Fig. 1)

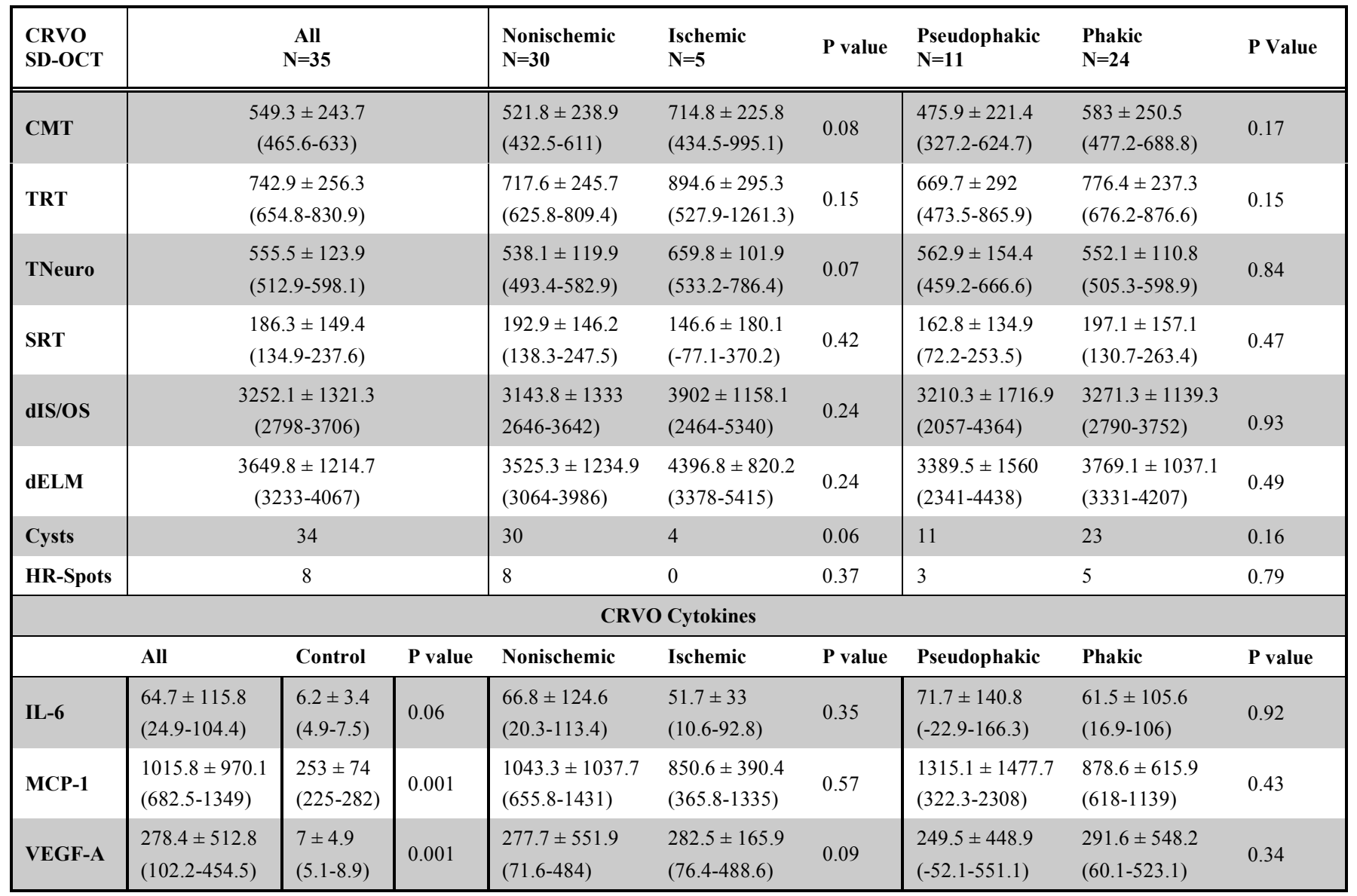

All measurements are depicted as mean values \pm standard deviation (SD) in $\mu \mathrm{m}$. The $95 \%$ confidence interval values are depicted in brackets; CMT $=$ central macular thickness, TRT=total retinal thickness; TNeuro=thickness neurosensorium; SRT=subretinal thickness; dIS/OS= discontinued inner and outer photoreceptor segment band in the fovea; $\mathrm{dELM}=$ discontinued external limiting membrane band; Cysts=intraretinal cysts; HR spots= hyperreflective spots. The absolute mean values of the vitreous cytokines \pm standard deviation (SD) are in $\mathrm{pg} / \mathrm{ml}$ with the $95 \%$ confidence interval values in brackets.

1037.7 (655.8-1431), and the VEGF-A level was $277.7 \pm$ 551.9 (71.6-484). In the ischemic group, the level of IL-6 was $51.7 \pm 33$ (CI 10.6-92.8, $\mathrm{P}=0.35$ ), and the level of MCP1 was $850.6 \pm 390.4$ (CI 365.8-1335, $\mathrm{P}=0.57$ ). The VEGF-A level was higher in the ischemic group than in the nonischemic group, at $282.5 \pm 165.9$ (CI 76.4-488.6). The differences between the lens status was not significant. IL-6 was $71.7 \pm 140.8(\mathrm{CI}-22.9-166.3)$ in the pseudophakic group and $61.5 \pm 105.6$ (CI 16.9-106, $\mathrm{P}=0.92$ ) in the phakic group. The levels of MCP-1 were 1315.1 \pm 1477.7 (CI 322.1-2308) and 878.6 \pm 615.9 (CI 618-1139, $\mathrm{P}=0.43$ ), while the level of VEGF-A was $249.5 \pm 448.9$ (CI $-52.1-$ 551.1) and 291.6 \pm 548.2 (CI 60.1-523.1, $\mathrm{P}=0.34$ ), respectively.

\section{Correlation Between Cytokines}

In the CRVO group, all cytokines were positively correlated with one other. IL-6 was positively correlated (Table 3) with both MCP-1 $(\mathrm{r}=0.82 ; \mathrm{P}<0.0001)$ and VEGF-A $(\mathrm{r}=0.75 ; \mathrm{P}<0.0001), \mathrm{MCP}-1$ was correlated with VEGF-A $(\mathrm{r}=0.62 ; \mathrm{P}<0.0001)$. This was confirmed in the nonischemic CRVO subgroup analysis, where the IL-6 level was correlated with MCP-1 $(\mathrm{r}=0.83 ; \mathrm{P}<0.0001)$ and VEGF-A $(\mathrm{r}=0.76 ; \mathrm{P}<0.0001)$, and MCP-1 levels were correlated with VEGF-A $(\mathrm{r}=0.63 ; \mathrm{P}<0.0002)$. In the ischemic subgroup, however, there was no significant correlation among the cytokines. Analysis of the pseudophakic versus the phakic subgroup yielded positive correlation coefficients for all three cytokines. In the pseudophakic group, the following correlations were observed: IL-6 and MCP-1: $\mathrm{r}=0.71$, $\mathrm{P}<0.0001$; IL-6 and VEGF-A: $\mathrm{r}=0.66, \mathrm{P}<0.0004$; MCP-1 and VEGF-A: $\mathrm{r}=0.51, \mathrm{P}<0.01$. In the phakic group, the following correlations were observed: IL-6 and MCP-1: $\mathrm{r}=0.98$, $\mathrm{P}<0.0001$; IL-6 and VEGF-A: $\mathrm{r}=0.99, \mathrm{P}<0.0001$; $\mathrm{MCP}-1$ and VEGF-A: $r=0.99, \mathrm{P}<0.0001$.

\section{Correlation of Cytokines with SD-OCT}

IL-6 correlated more often with SD-OCT parameters than did MCP-1 (five times versus three times). IL-6 correlated significantly with CMT $(\mathrm{r}=0.53 ; \mathrm{P}<0.001)$, TRT $(\mathrm{r}=0.49$; $\mathrm{P}<0.003)$, SRT $(\mathrm{r}=0.41 ; \mathrm{P}<0.02)$, dIS/OS $(\mathrm{r}=0.56 ; \mathrm{P}<0.001)$, and $\mathrm{dELM} \quad(\mathrm{r}=0.58 ; \quad \mathrm{P}<0.003) . \quad \mathrm{MCP}-1 \quad$ correlated significantly with SRT $(\mathrm{P}<0.04)$; dIS/OS $(\mathrm{r}=0.38 ; \mathrm{P}<0.02)$, and dELM $(r=0.36 ; \mathrm{p}<0.03)$. VEGF-A did not correlate with CRVO-associated changes in SD-OCT.

\section{Visual Acuity}

Visual acuity was analyzed with LogMAR values and correlated to objective SD-OCT parameters and the vitreal 
Table 3. Spearman Rang Correlation Matrix

\begin{tabular}{|c|c|c|c|c|c|c|c|c|c|c|c|c|}
\hline & VA & CMT & TRT & TNeuro & SRT & dIS/OS & dELM & Cysts & Ischemic & IL-6 & MCP-1 & VEGF-A \\
\hline VA & & $\begin{array}{l}0.15 \\
(0.39)\end{array}$ & $\begin{array}{l}0.14 \\
(0.42)\end{array}$ & $\begin{array}{l}-0.04 \\
(0.80)\end{array}$ & $\begin{array}{l}0.27 \\
(0.11)\end{array}$ & $\begin{array}{l}0.26 \\
(0.13)\end{array}$ & $\begin{array}{l}0.16 \\
(0.35)\end{array}$ & $\begin{array}{l}-0.04 \\
(0.81)\end{array}$ & $\begin{array}{l}-0.27 \\
(0.12)\end{array}$ & $\begin{array}{l}0.25 \\
(0.15)\end{array}$ & $\begin{array}{l}0.26 \\
(0.12)\end{array}$ & $\begin{array}{l}0.15 \\
(0.8)\end{array}$ \\
\hline CMT & & & $\begin{array}{l}0.83 \\
\mathbf{( 0 . 0 0 1 )}\end{array}$ & $\begin{array}{l}0.37 \\
\mathbf{( 0 . 0 3 )}\end{array}$ & $\begin{array}{l}0.42 \\
(\mathbf{0 . 0 1 )}\end{array}$ & $\begin{array}{l}0.49 \\
(\mathbf{0 . 0 0 3 )}\end{array}$ & $\begin{array}{l}0.43 \\
(\mathbf{0 . 0 1 )}\end{array}$ & $\begin{array}{l}-0.52 \\
(\mathbf{0 . 0 0 2})\end{array}$ & $\begin{array}{l}-0.30 \\
(0.08)\end{array}$ & $\begin{array}{l}0.53 \\
\mathbf{( 0 . 0 0 1 )}\end{array}$ & $\begin{array}{l}0.21 \\
(0.23)\end{array}$ & $\begin{array}{l}0.33 \\
(0.05)\end{array}$ \\
\hline TRT & & & & $\begin{array}{l}0.55 \\
(\mathbf{0 . 0 0 1 )}\end{array}$ & $\begin{array}{l}0.49 \\
(\mathbf{0 . 0 0 3})\end{array}$ & $\begin{array}{l}0.45 \\
(\mathbf{0 . 0 1 )}\end{array}$ & $\begin{array}{l}0.44 \\
(\mathbf{0 . 0 1 )}\end{array}$ & $\begin{array}{l}-0.22 \\
(0.21)\end{array}$ & $\begin{array}{l}-0.25 \\
(0.14)\end{array}$ & $\begin{array}{l}0.49 \\
(\mathbf{0 . 0 0 3 )}\end{array}$ & $\begin{array}{l}0.29 \\
(0.10)\end{array}$ & $\begin{array}{l}0.33 \\
(0.06)\end{array}$ \\
\hline TNeuro & & & & & $\begin{array}{l}0.18 \\
(0.30)\end{array}$ & $\begin{array}{l}0.41 \\
(\mathbf{0 . 0 2})\end{array}$ & $\begin{array}{l}0.45 \\
\mathbf{( 0 . 0 1 )}\end{array}$ & $\begin{array}{l}-0.02 \\
(0.90)\end{array}$ & $\begin{array}{l}-0.32 \\
(0.07)\end{array}$ & $\begin{array}{l}0.18 \\
(0.30)\end{array}$ & $\begin{array}{l}0.10 \\
(0.57)\end{array}$ & $\begin{array}{l}0.18 \\
(0.30)\end{array}$ \\
\hline SRT & & & & & & $\begin{array}{l}0.51 \\
(\mathbf{0 . 0 0 2})\end{array}$ & $\begin{array}{l}0.54 \\
(\mathbf{0 . 0 0 1 )}\end{array}$ & $\begin{array}{l}-0.13 \\
(0.47)\end{array}$ & $\begin{array}{l}0.15 \\
(0.39)\end{array}$ & $\begin{array}{l}0.41 \\
(\mathbf{0 . 0 2})\end{array}$ & $\begin{array}{l}0.35 \\
(\mathbf{0 . 0 4 )}\end{array}$ & $\begin{array}{l}0.05 \\
(0.79)\end{array}$ \\
\hline dIS/OS & & & & & & & $\begin{array}{l}0.91 \\
\mathbf{( 0 . 0 0 1 )}\end{array}$ & $\begin{array}{l}-0.28 \\
(0.11)\end{array}$ & $\begin{array}{l}-0.21 \\
(0.21)\end{array}$ & $\begin{array}{l}0.56 \\
\mathbf{( 0 . 0 0 1 )}\end{array}$ & $\begin{array}{l}0.30 \\
(\mathbf{0 . 0 8})\end{array}$ & $\begin{array}{l}0.20 \\
(0.24)\end{array}$ \\
\hline dELM & & & & & & & & $\begin{array}{l}-0.28 \\
(0.11)\end{array}$ & $\begin{array}{l}-0.21 \\
(0.21)\end{array}$ & $\begin{array}{l}0.58 \\
(\mathbf{0 . 0 0 3 )}\end{array}$ & $\begin{array}{l}0.38 \\
(\mathbf{0 . 0 2})\end{array}$ & $\begin{array}{l}0.35 \\
(0.04)\end{array}$ \\
\hline Cysts & & & & & & & & & $\begin{array}{l}0.40 \\
(\mathbf{0 . 0 2})\end{array}$ & $\begin{array}{l}-0.12 \\
(0.50)\end{array}$ & $\begin{array}{l}0.19 \\
(0.28)\end{array}$ & $\begin{array}{l}-0.02 \\
(0.90)\end{array}$ \\
\hline Ischemic & & & & & & & & & & $\begin{array}{l}-0.17 \\
(0.33)\end{array}$ & $\begin{array}{l}-0.11 \\
(0.55)\end{array}$ & $\begin{array}{l}-0.28 \\
(0.10)\end{array}$ \\
\hline IL-6 & & & & & & & & & & & $\begin{array}{l}0.82 \\
(\mathbf{0 . 0 0 1 )}\end{array}$ & $\begin{array}{l}0.68 \\
(\mathbf{0 . 0 0 1 )}\end{array}$ \\
\hline MCP-1 & & & & & & & & & & & & $\begin{array}{l}0.64 \\
(\mathbf{0 . 0 0 1 )}\end{array}$ \\
\hline VEGF-A & & & & & & & & & & & & \\
\hline
\end{tabular}

Subjective (logMar-VA) and objective (SD-OCT) values are correlated with each other and with the values for vitreal cytokines (IL-6, MCP-1, and VEGF-A). The results are represented with the correlation coefficient $\mathrm{r}(p$ values are in brackets). The statistically significant correlations are depicted as bold results.

cytokine values (Table 3). There was no significant correlation between any of the parameters and visual acuity.

\section{DISCUSSION}

We could demonstrate, that primarily the inflammatory cytokines were more often correlated with morphologic changes assessed by SD-OCT, whereas VEGF-A did not correlate with CRVO-associated changes in SD-OCT.

Recent studies with SD-OCT have shown that macular edema secondary to retinal vein occlusion is often characterized by numerous cystoid spaces and marked retinal swelling, especially in the outer retinal layers. We are not aware, that there is a correlation of SD-OCT parameters with intraocular cytokine levels published up to date. In our study, IL-6 correlated more often with SD-OCT parameters than MCP-1, whereas VEGF-A did not correlate with CRVOassociated changes in SD-OCT (Table 3). CRVO macular edema is often accompanied by serous retinal detachment, which might occur as pointed or dome-shaped and might be associated with a poorer visual acuity prognosis [1]. The most suitable predictor of visual acuity, however, seems to be the integrity of the photoreceptor layer and the integrity of the external limiting membrane $[3,4]$. Subretinal thickness, dIS/OS, and dELM were significantly correlated with the inflammatory marker IL-6 and not with VEGF-A. The visual acuity at the time of combination therapy was not correlated with objective SD-OCT parameters or the cytokines. Cystoid spaces themselves are often accompanied by hyperreflective spots, which might indicate chronicity [17]. Cystoid spaces and hyperreflective spots were correlated with central macular thickness and IL-6, which might underline chronicity. MCP-1, however, was not correlated with cystoid space or with hyperreflective spots. Generally, the role of MCP-1 in the pathophysiology of RVO is until today not well perceived. It has strong eosinophilic chemotactic properties and is crucial in monocyte recruitment at the endocytes, which supports the role of eosinophils in tissue remodeling [18].

It is noteworthy that in our study all cytokines are positively correlated with each other (Table 3 ), which was highly statistically significant. Because of one limitation of our study, the relatively small number of ischemic CRVO patients $(n=5)$, we can only speculate about the implication of the results in terms of the comparison between ischemic versus nonischemic patients. While Noma et al. were able to demonstrate elevated IL-6 and VEGF levels in 18 ischemic CRVOs (versus 9 nonischemic CRVO) [7], we could not confirm this observation (Fig. 3). There was a trend towards elevated VEGF-A levels in the ischemic group $(\mathrm{p}=0.09)$, but the correlation among the cytokines was insignificant, while there was a positive correlation between the cytokines in the 


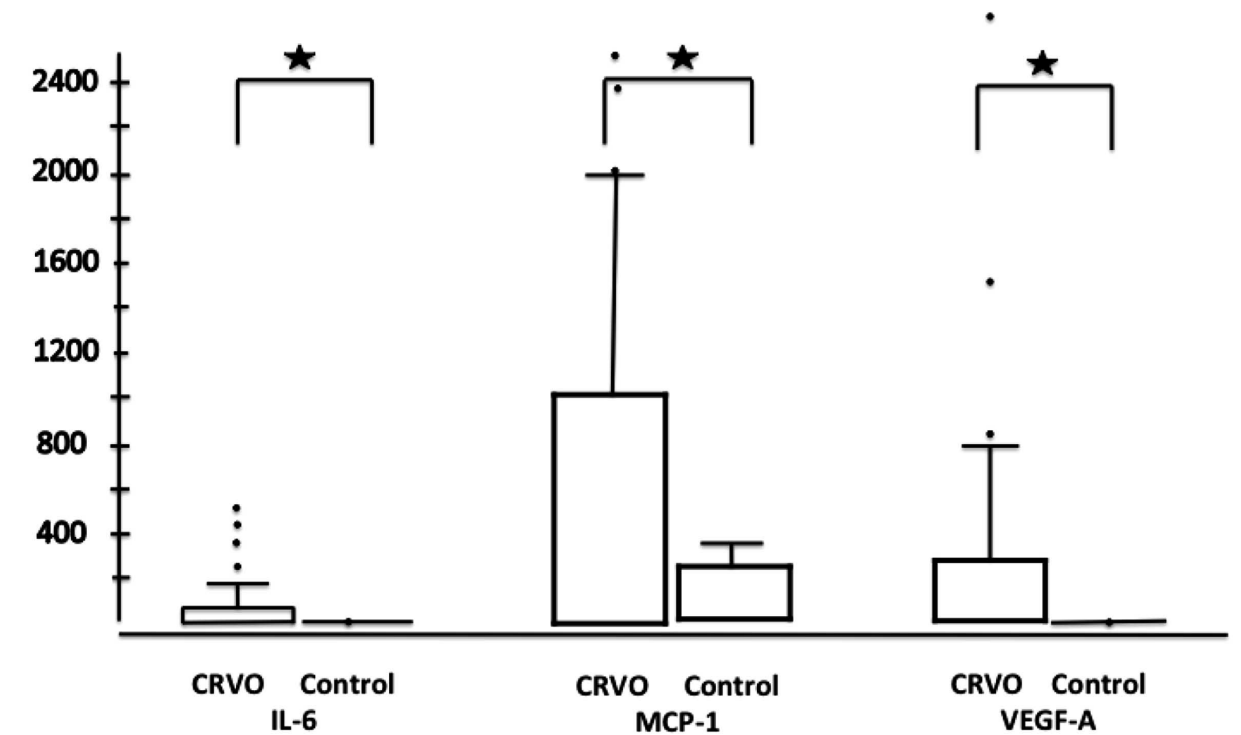

Fig. (2). Bar plots with the values of cytokines (statistical extremes are marked with dots) for all CRVO patients (left bar plots; $\mathrm{n}=35$ ) versus the control group (right bar plot; $\mathrm{n}=28$ ); significant differences are noted with stars.

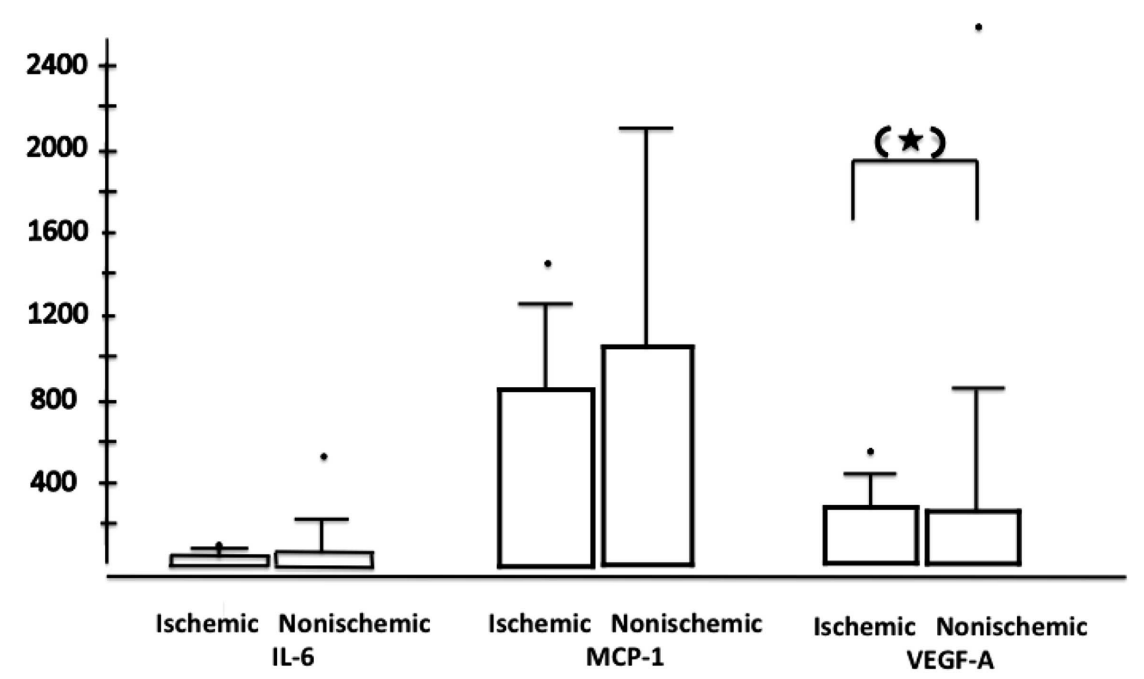

Fig. (3). Bar plots with the values of cytokines (statistical extremes are marked with dots) for ischemic CRVO patients (left bar plots; $\mathrm{n}=15$ ) versus non-ischemic CRVO patients (right bar plot; $n=30$ ); $p=0.09$ is marked with a star in brackets.

nonischemic group. Based on routine clinical practice [10, 19] and previous preclinical publications [20,21], it is likely that in CRVO with retinal ischemia, VEGF and IL-6 are both higher than in nonischemic CRVO. Cataract extraction after ischemic CRVO may imply a clinical risk of developing rubeosis iridis, but generally the implication of lens status (phakic or pseudophakic) is not well understood. We did not observe a significant difference between the two subgroups. The limitations of our study are a small sample size, which may have to oversee especially in the ischemic CRVO group significant differences.

In conclusion, we demonstrated significantly higher values of inflammatory and proangiogenic cytokines in eyes with "fresh", treatment-naïve CRVO eyes as compared with control eyes. Although there was no correlation between morphologic SD-OCT parameters and visual acuity seven months after CRVO onset, inflammatory cytokines, IL-6 and MCP-1 were more often correlated with predictive morphologic changes (SRT, IS/OS, ELM), which are clinically important in visual acuity prognosis, than VEGFA. VEGF-A had a tendency to be higher in the ischemic than in the nonischemic CRVO group.

\section{CONFLICT OF INTEREST}

The authors confirm that this article content has no conflicts of interest.

\section{ACKNOWLEDGEMENTS}

The Adolf Messer Foundation, Königstein, Germany, supports the research group.

\section{REFERENCES}

[1] Tsujikawa A, Sakamoto A, Ota M, et al. Serous retinal detachment associated with retinal vein occlusion. Am J Ophthalmol 2010; 149(2): 291-301 e5. 
[2] Yamaike N, Tsujikawa A, Ota M, et al. Three-dimensional imaging of cystoid macular edema in retinal vein occlusion. Ophthalmology 2008; 115(2): 355-62 e2.

[3] Ota M, Tsujikawa A, Kita M, et al. Integrity of foveal photoreceptor layer in central retinal vein occlusion. Retina 2008; 28(10): 1502-8.

[4] Shin HJ, Chung H, Kim HC. Association between integrity of foveal photoreceptor layer and visual outcome in retinal vein occlusion. Acta Ophthalmologica 2011; 89(1): e35-40.

[5] Kriechbaum K, Prager F, Geitzenauer W, et al. Association of retinal sensitivity and morphology during antiangiogenic treatment of retinal vein occlusion over one year. Ophthalmology 2009; 116(12): 2415-21.

[6] Funk M, Kriechbaum K, Prager F, et al. Intraocular concentrations of growth factors and cytokines in retinal vein occlusion and the effect of therapy with bevacizumab. Invest Ophthalmol Vis Sci 2009; 50(3): 1025-32.

[7] Noma H, Funatsu H, Mimura T, Harino S, Hori S. Vitreous levels of interleukin-6 and vascular endothelial growth factor in macular edema with central retinal vein occlusion. Ophthalmology 2009; 116(1): 87-93.

[8] Noma H, Funatsu H, Mimura T, Shimada K. Increase of aqueous inflammatory factors in macular edema with branch retinal vein occlusion: a case control study. J Inflamm (Lond) 2010; 7: 44.

[9] Jo N, Wu GS, Rao NA. Upregulation of chemokine expression in the retinal vasculature in ischemia-reperfusion injury. Invest Ophthalmol Vis Sci 2003; 44(9): 4054-60.

[10] Ryan SJ. Retina. 4th ed. In: Schachat AP, Ed. Philadelphia: MOSBY 2006.

[11] Pe'er J, Folberg R, Itin A, Gnessin H, Hemo I, Keshet E. Vascular endothelial growth factor upregulation in human central retinal vein occlusion. Ophthalmology 1998; 105(3): 412-6.
[12] Cohen T, Nahari D, Cerem LW, Neufeld G, Levi BZ. Interleukin 6 induces the expression of vascular endothelial growth factor. J Biol Chem 1996; 271(2): 736-41.

[13] Noma H, Funatsu H, Mimura T, Eguchi S, Shimada K, Hori S Vitreous levels of pigment epithelium-derived factor and vascular endothelial growth factor in macular edema with central retinal vein occlusion. Curr Eye Res 2011; 36(3): 256-63.

[14] Noma H, Funatsu H, Mimura T, Eguchi S, Shimada K. Role of soluble vascular endothelial growth factor receptor-2 in macular oedema with central retinal vein occlusion. Br J Ophthalmol 2011; 95(6): 788-92.

[15] Koss MJ, Pfister M, Rothweiler F, et al. Comparison of cytokine levels from undiluted vitreous of untreated patients with retinal vein occlusion. Acta Ophthalmol 2012; 90(2): e98-e103.

[16] Koss MJ, Naser H, Sener A, et al. Combination therapy in diabetic macular oedema and retinal vein occlusion - past and present. Acta Ophthalmol 2012; 90(6): 580-9

[17] Horii T, Murakami T, Nishijima K, Sakamoto A, Ota M, Yoshimura N. Optical coherence tomographic characteristics of microaneurysms in diabetic retinopathy. Am J Ophthalmol 2010; 150(6): 840-8.

[18] Schober A, Zernecke A. Chemokines in vascular remodeling Thromb Haemost 2007; 97(5): 730-7.

[19] Stefansson E. Physiology of vitreous surgery. Graefes Arch Clin Exp Ophthalmol 2009; 247(2): 147-63.

[20] Aiello LP, Northrup JM, Keyt BA, Takagi H, Iwamoto MA Hypoxic regulation of vascular endothelial growth factor in retinal cells. Arch Ophthalmol 1995; 113(12): 1538-44.

[21] Ali MH, Schlidt SA, Chandel NS, Hynes KL, Schumacker PT, Gewertz BL. Endothelial permeability and IL-6 production during hypoxia: role of ROS in signal transduction. Am J Physiol 1999; 277(5 Pt 1): L1057-65.

(C) Koss et al.; Licensee Bentham Open.

This is an open access article licensed under the terms of the Creative Commons Attribution Non-Commercial License (http://creativecommons.org/licenses/by$\mathrm{nc} / 3.0 /$ ) which permits unrestricted, non-commercial use, distribution and reproduction in any medium, provided the work is properly cited. 